\title{
Drawing Sustainability: \\ Helping students to know what they know
}

5th World Symposium on Sustainable

Development at Universities (WSSD-U-2020)

Dr Kay Emblen-Perry

Worcester Business School 


\section{Drawing Sustainability: Helping students to know what they know}

- The importance of learning recognition

- The value of drawing as a teaching tool

- Drawing Sustainability as a learning activity

- Outcomes and reflections on learning

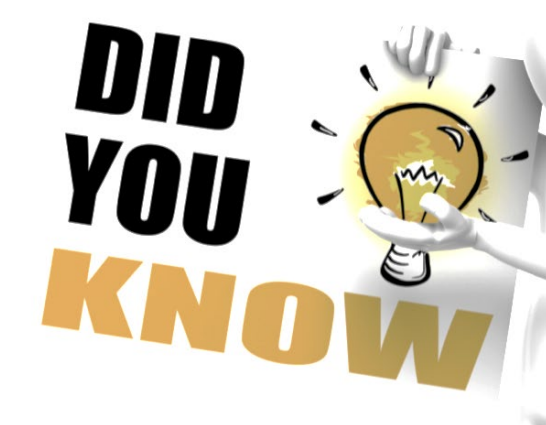




\section{Context: The importance of learning recognition}

- Being able to judge self-knowledge enhances a leaner's education (Kurnaz and Cimer, 2010)

- Self-analysis may encourage further learning through:

$\checkmark$ Recognition of own knowledge, strengths and weaknesses (Hannon, McBride and Burns, 2004)

$\checkmark$ Knowledge construction (Rieser, 2004)

$\checkmark$ Sense making (Quintana et al., 1999)

$\checkmark$ Feedback literacy (Carless and Boud, 2018)

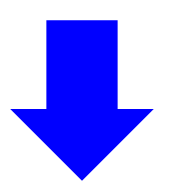

Those able to reflect on, and become aware of their abilities, are likely to perform better than those who do not (Flavell, 1976)

"To know what you know and what you do not know, that is true knowledge"

Confucius 


\section{Context: The value of drawing as a teaching tool}

- Drawing can be a powerful teaching tool as it:

$\checkmark$ Encourages learners to create, develop, record and communicate thoughts and ideas (Van Meter and Garner, 2005)

$\checkmark$ Promotes critical thinking (Quillin and Thomas, 2015)

$\checkmark$ Builds self-esteem and self-confidence (Jones, 1997)

$\checkmark$ Encourages students to share their thinking between peers (Ainsworth, Prain and Tytley, 2011)

$\checkmark$ Encourages students to apply what they have learned and recreate it in another format (Griffith and Burns, 2014)

$\checkmark$ Offers students the opportunity to see previously unrecognized knowledge (Vygotsky, 1978)

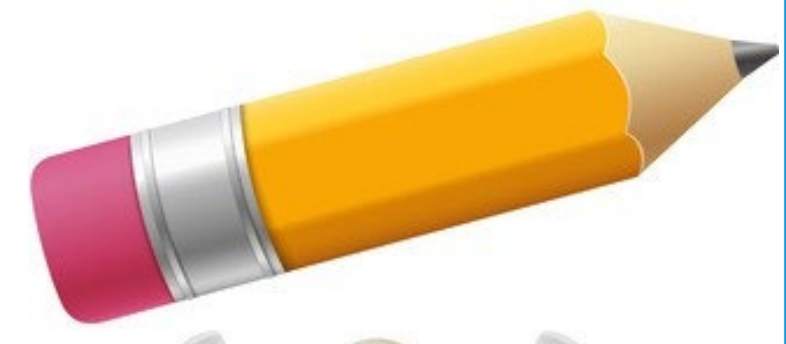




\section{The value of drawing for educators}

- Drawing can also be used to:

$\checkmark$ Expose misconceptions (Dikmenli, 2010)

$\checkmark$ Enhance motivation (Glynn and Muth, 2008)

$\checkmark$ Encourage the connection of concepts (Long et al., 2014)

$\checkmark$ Provide a learning benchmark (Brooks, 2005)

These opportunities provided through drawing help staff to support students to understand the interconnected problems, complexities and opportunities that are inherent in Education for Sustainability and the SDGs 


\title{
The value of drawing for learning recognition
}

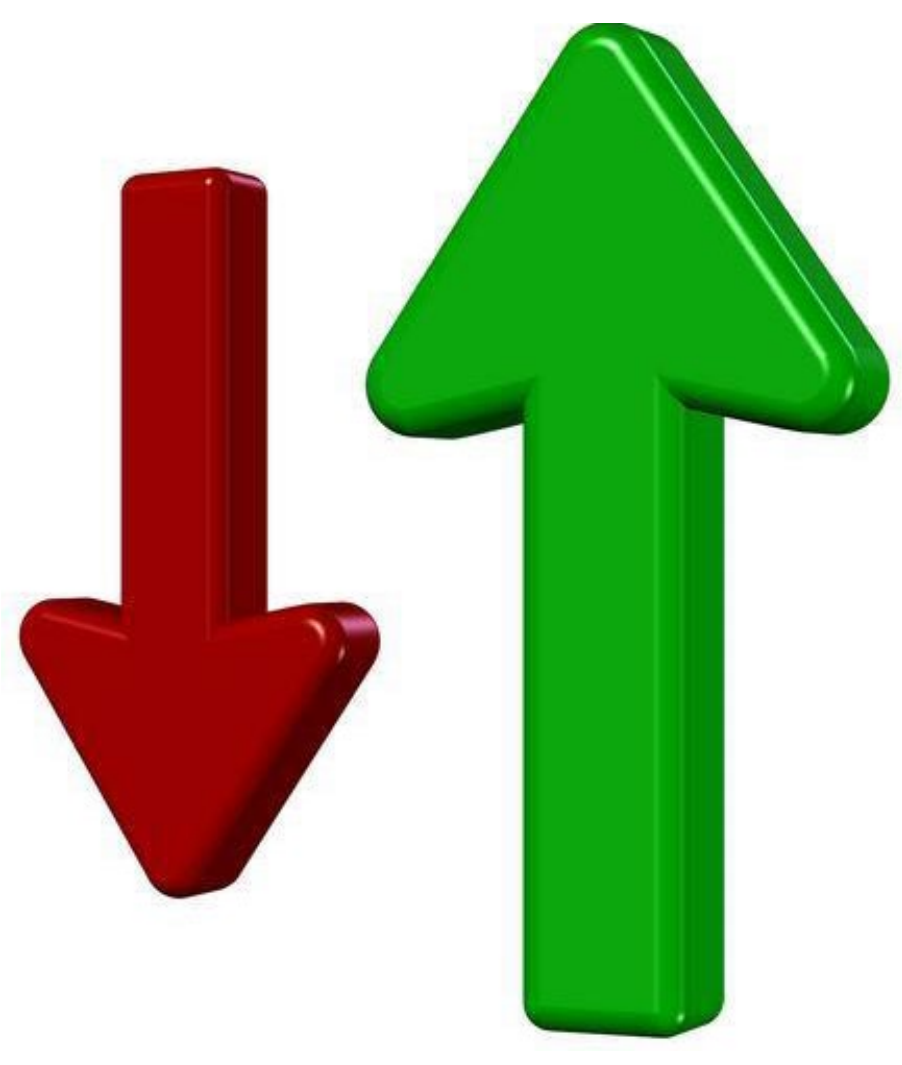

\author{
I adopted \\ Drawing Sustainability \\ as a teaching tool to \\ facilitate reflection, \\ knowledge construction \\ and self-analytical \\ learning \\ in a way that \\ encourages students \\ to apply \\ their thinking and \\ recognize their \\ knowledge
}

Drawing Sustainability presents an opportunity for students to ask themselves "What do I know?" and "What else do I need to know?"...

... and for educators to recognize what students need to know and what they need to un-know 


\section{Drawing Sustainability: The learning activity}

- The task of Drawing Sustainability: "In small groups and using the pens and paper provided 1) Draw your understanding of 'sustainability' and 2) Share your thoughts with the class"

- Students are given the same task of Drawing Sustainability in the first and last lectures of the module (Phase 1 and Phase 2 of the study)

- Each group is given resources of 1 piece of flip chart paper and 4 marker pens of different colours

- As students prefer collaborative learning activities they are encouraged to undertake the activity in self-formed groups of between 2-5

- Reflections on learning through drawing are collected following Phase 2
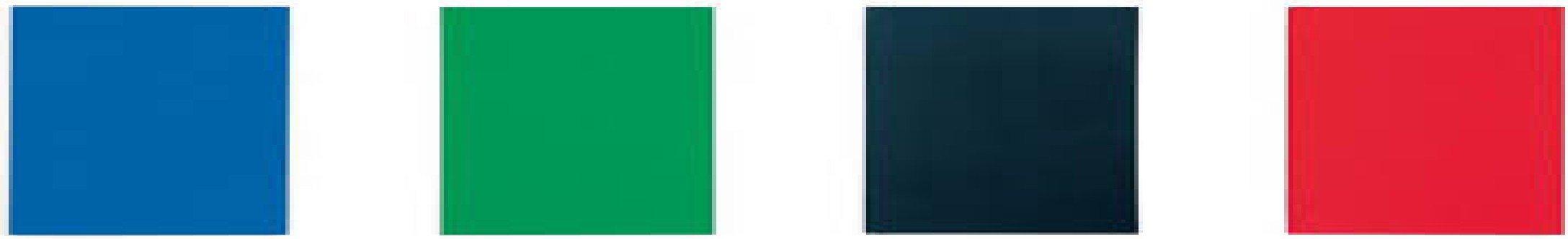


\section{Examples of Drawing Sustainability: Phase 1}

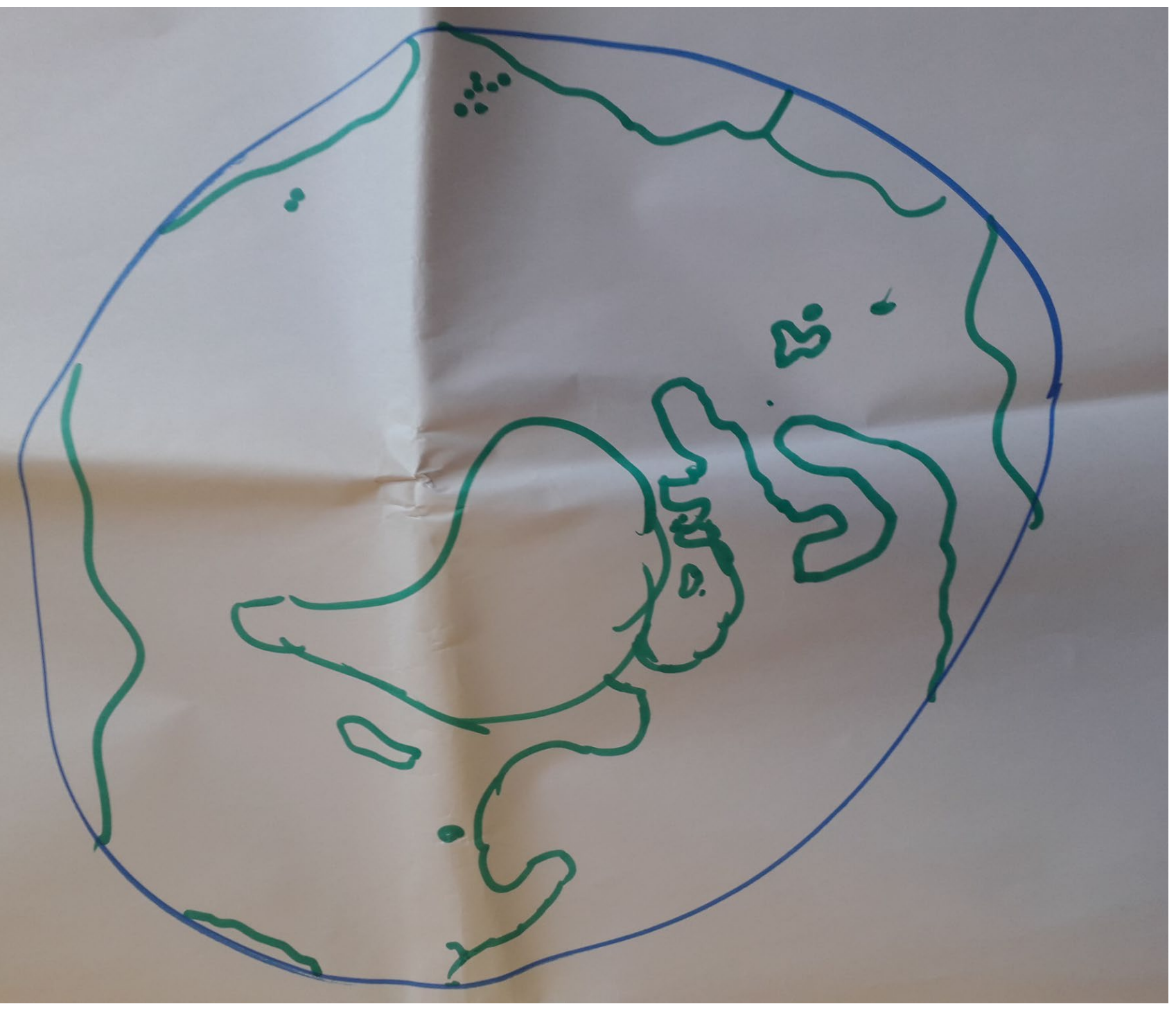

Group 4 Secondyear students 2016-17 


\section{Examples of Drawing Sustainability: Phase 2}

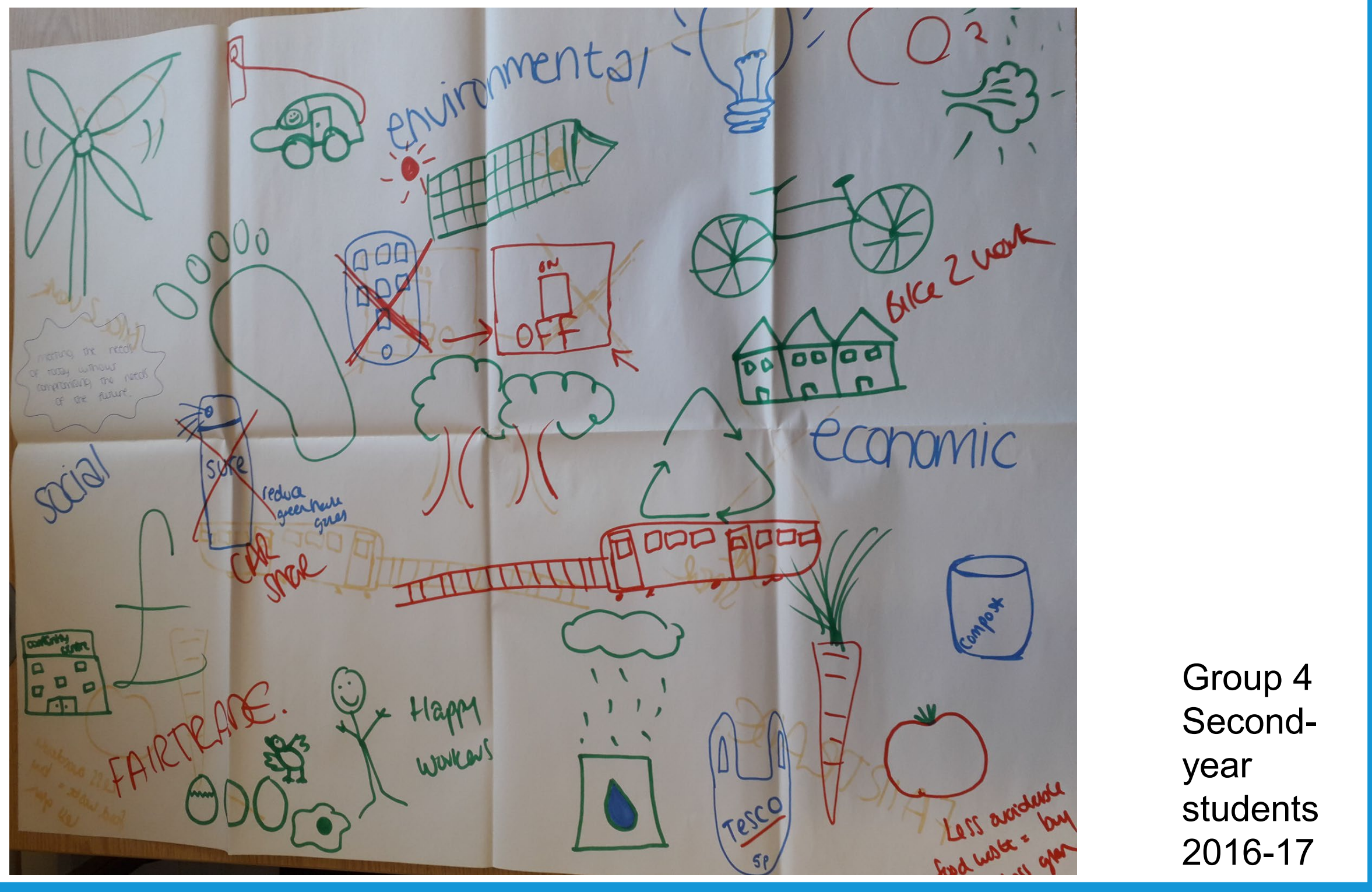




\section{Examples of Drawing Sustainability: Phase 1}

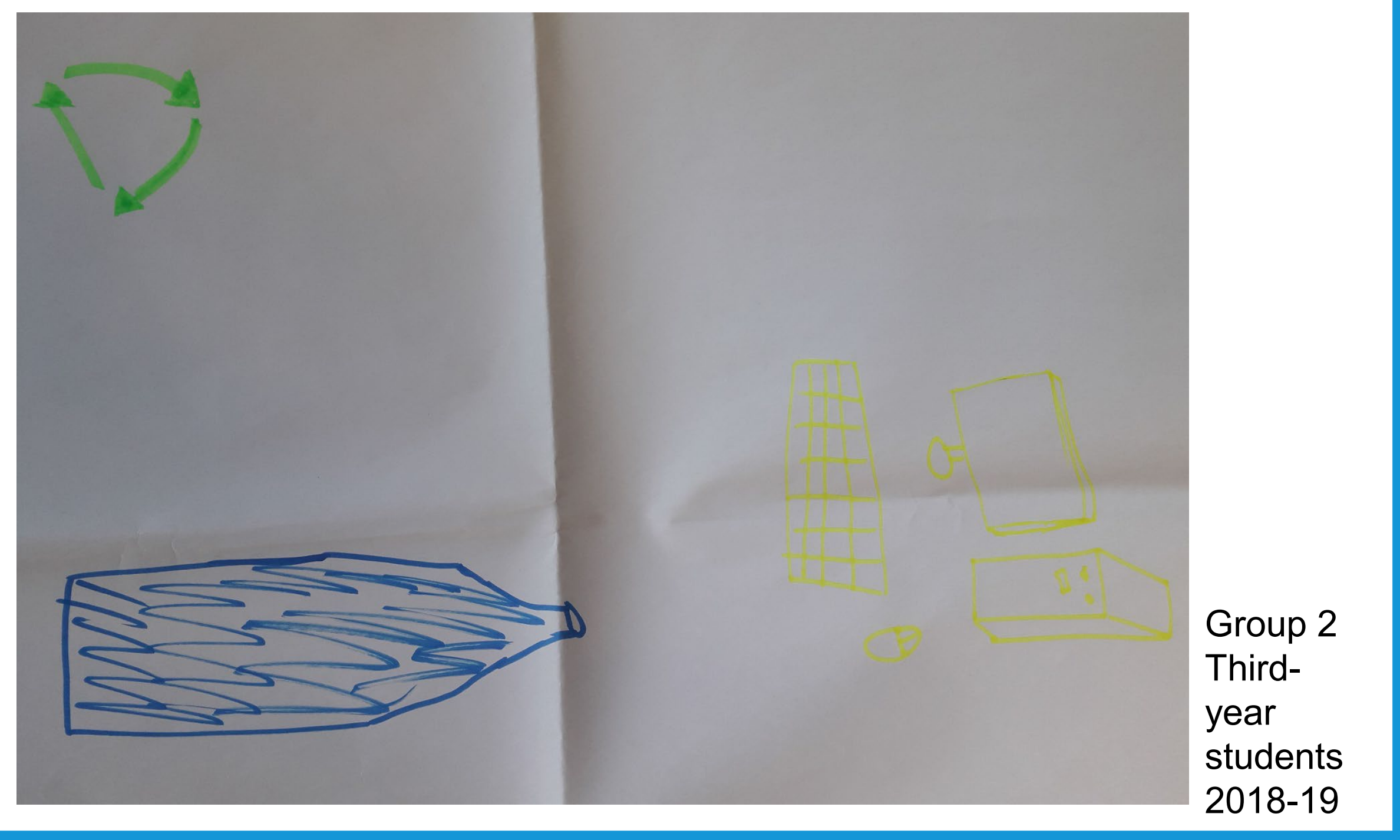




\section{Examples of Drawing Sustainability: Phase 2}

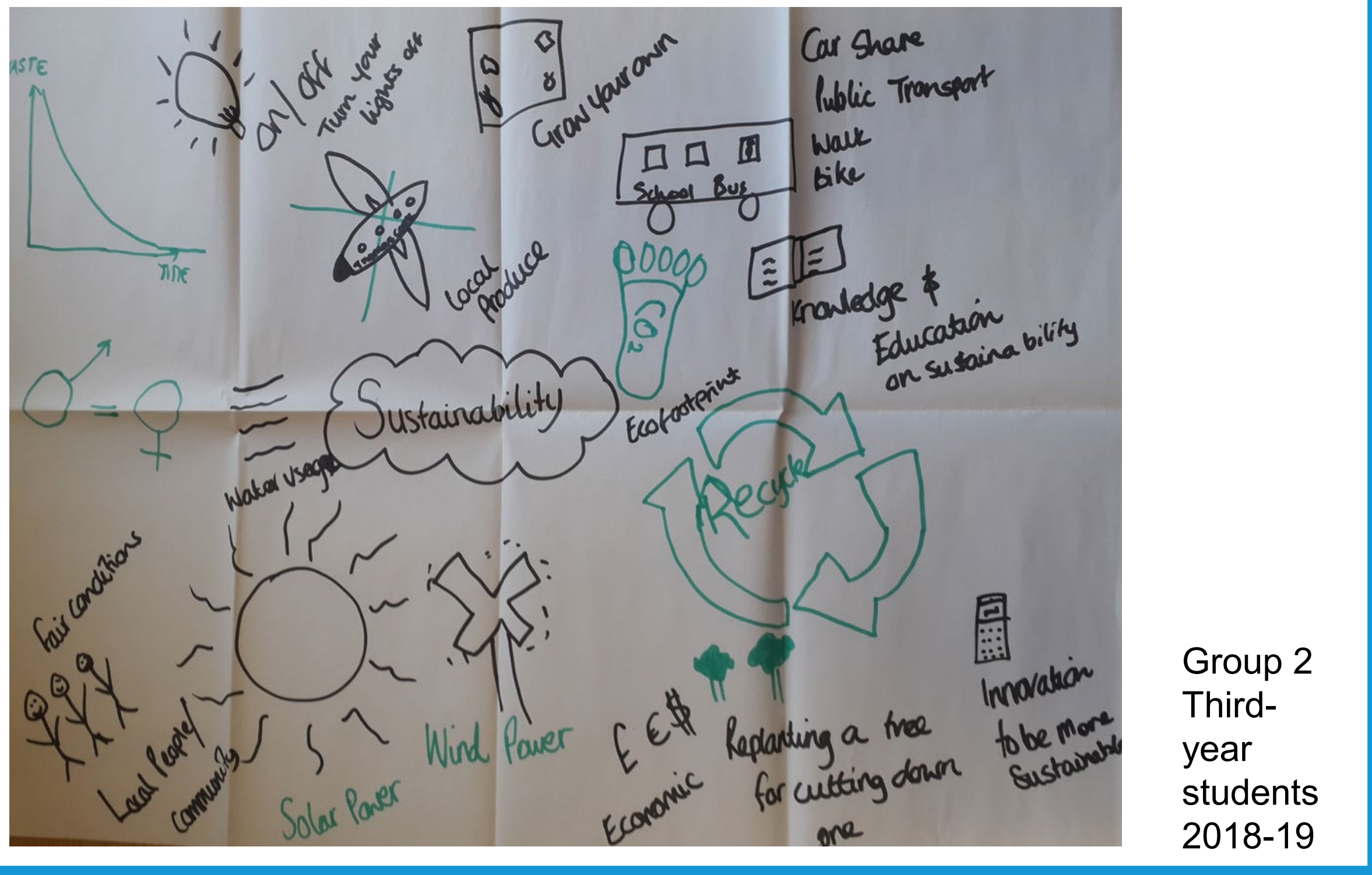




\section{Activity challenges: Student engagement}

Concern "I can't draw" - students are risk adverse and frequently insecure about their ability to draw

Response:

- The purpose of the activity and intended use of the drawings is highlighted and unimportance of drawing skills in emphasized

- Praise is given to each group during the activity e.g. a particular piece of sustainability content or the recognition of its' complexity

Outcome:

- Students generally forget they thought they couldn't draw 


\section{Learning outcomes achieved}

- Recognition of learning:

$\checkmark$ "Using pictures contributed to my sustainability knowledge" (third-year student)

$\checkmark$ "I know I have gained new skills and knowledge" (third-year student)

$\checkmark$ "Drawing helped me test my current knowledge" (second-year student)

$\checkmark$ "Now I know I learned a lot" (second-year student)

- Alternative ways of thinking required achieve SDGs:

$\checkmark$ "Drawing can help you think outside the box and challenge yourself" (third-year student)

$\checkmark$ "I have developed more innovative ways of thinking" (second-year student)

$\checkmark$ "It helped me improve my critical thinking and analysis and I now take into account other people's arguments and views" (third-year student) 


\section{Learning outcomes achieved}

- Recognition of importance of different learning approaches:

$\checkmark$ "I know I learned a lot from my friends" (second-year student)

$\checkmark$ "I have been able to collaborate with individuals who provide interesting views" (third-year student)

$\checkmark$ "Drawing helped me to feel free to express my ideas" (third-year student)

- Higher cognitive skills and greater confidence:

$\checkmark$ "I have become more confident about demonstrating my opinion" (second-year student)

$\checkmark$ "It has given me a better understanding of how to communicate my ideas" (second-year student)

- Relating personal sustainability practices to society and the environment:

$\checkmark$ "I now care about better solutions" (second-year student)

$\checkmark$ "Don't be shy to speak about global topics" (second-year student) 


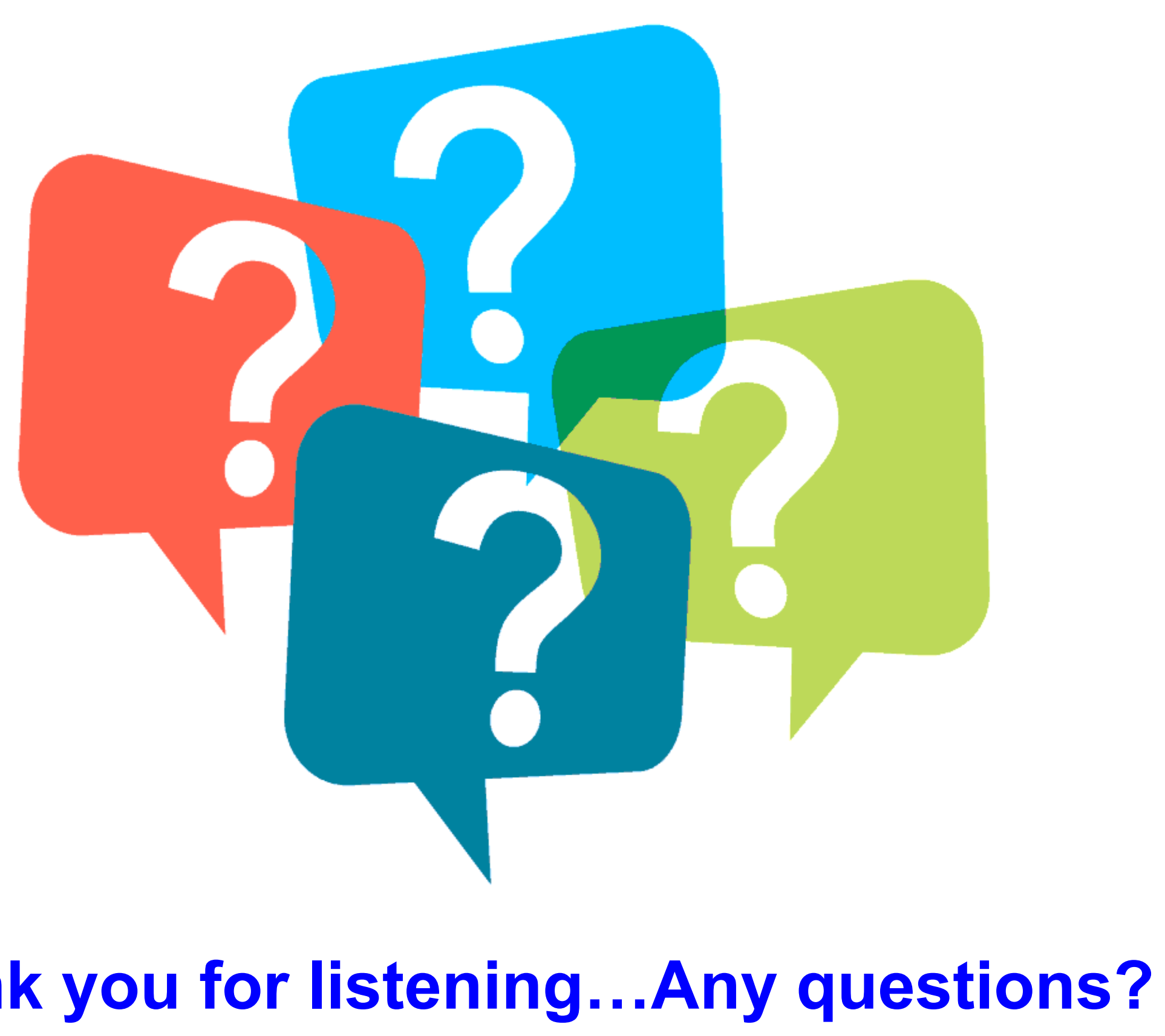

Thank you for listening...Any questions? 